\title{
SUR LES TRACES DE LA PREMIÈRE TRADUCTION TCHÈQUE DE ZONE DE GUILLAUME APOLLINAIRE
}

Kateřina DRSKOVÁ

Université de Bohême du Sud, České Budějovice

\section{Introduction}

Cent ans s'étaient écoulés, en avril 2013, depuis la première parution d'Alcools, recueil rassemblant les poésies de Guillaume Apollinaire écrites entre 1898 et 1912 et représentant l'aboutissement de son «long mûrissement» poétique : «il en présente toutes les étapes, toutes les ressources et toutes les tendances dans leur diversité $»^{1}$. Michèle Touret souligne le caractère hétérogène de cette œuvre qui de par son organisation pourrait sembler hétéroclite, disparate, et était effectivement considérée comme telle par une partie de la critique de l'époque. «Il n'y a en effet aucune unité apparente de sujet, pas d'homogénéité esthétique, aucun ordre chronologique. ${ }^{2}$ Toutefois, la composition du volume n'aurait rien d'aléatoire, Apollinaire l'ayant soumise à une logique propre découlant de sa conception lyrique :

«L'ordre n'est pas représentatif d'un parcours réel, mais la composition abstraite est certainement rigoureuse, fondée sur deux principes antagoniques : une continuité souterraine des interrogations et des souvenirs, avec des résurgences soudaines, et des ruptures de ton, de forme, de sujets, continuelles et très fortes, conformément aux desseins poétiques d'Apollinaire [...] La diversité n'est pas ici signe de virtuosité ni de dispersion mais d'intensité dramatique pour un être non pas incohérent mais divers, non pas sceptique mais inquiet et toujours en mouvement. ${ }^{3}$

Dans cet ordre d'idées, la place conférée à Zone, le poème chronologiquement composé en dernier, au tout début du recueil, est symptomatique. Ce choix annonce d'emblée la polyphonie thématique du recueil dont le sujet lyrique constitue la clé de voûte, la présence d'un mouvement allant de la tradition vers la modernité sans pour autant rejeter la première, le dynamisme, la variabilité, l'inspiration par le monde contemporain et l'intention du poète d' " assurer un renouveau lyrique et créer une poétique de la surprise. ${ }^{4}$ Le recueil devient une des œuvres poétiques les plus significatives et les plus influentes de la modernité, faisant «figure de texte charnière où se reconnait la transition entre deux siècles $»^{5}$.

Lors des premières décennies du $20^{\mathrm{e}}$ siècle, les milieux littéraires tchèques étaient à l'écoute des tendances esthétiques nouvelles venues d'ailleurs, accordant - outre les littératures anglo-saxonne, nordique et russe - une attention privilégiée

\footnotetext{
${ }^{1}$ Michèle Touret, Histoire de la littérature française $d u X X^{e}$ s., tome I, Presses universitaires de Rennes, p. 169.

${ }^{2}$ Ibidem, p. 169.

${ }^{3}$ Ibidem, p. 169-171.

${ }^{4}$ Ibidem, p. 169.

${ }^{5}$ Histoire de la France littéraire, vol. III, Modernités, (P. Berthier, M. Jarrety dir.), Paris, Quadrige/PUF, p. 301.

Echo des études romanes XI/2, $2015 \quad$ - 97 - ISSN: 1804-8358 (Online)
} 
à la littérature française. Cette orientation constituait le prolongement d'une tendance existant déjà au siècle précédent :

«la ligne du réalisme et du naturalisme tchèques a été influencée par l'objectivité de Flaubert, le style rude et concis de Maupassant, l' 'immoralité' naturaliste de Zola; les décadents ont vénéré Huysmans, l'ironique [...] L'entière poésie moderne tchèque de la fin du $19^{\mathrm{e}}$ siècle accusait l'effet de l'œuvre de Baudelaire, de Verlaine et d'autres 'poètes maudits'. » ${ }^{6}$

Par la suite, c'étaient les avant-gardes européennes du début du $20^{\mathrm{e}}$ siècle, particulièrement le futurisme italien et le cubisme (cubo-futurisme) français, qui ont fourni de nouvelles impulsions au développement de la poésie tchèque d'après-guerre. Dans la transmission et l'adoption de ces nouvelles tendances esthétiques, les traductions ont joué un rôle d'importance, voire un rôle décisif. L'évolution qu'a connue dans les années 20 la poésie tchèque, la mutation globale de sa structure et de ses fonctions, s'inspire dans une large mesure des traductions poétiques de Karel Čapek :

«Le début de cette mutation est marqué par les traductions de la poésie française de Karel Čapek. Dans ses traductions, Čapek a intégré tous les éléments principaux auxquels avait abouti la poésie tchèque lors de son évolution à partir des années 90 ; de cette manière, il a constitué l'axe du développement postérieur de cette poésie. Ceci est particulièrement visible sur le plan linguistique, où Čapek a soutenu la tendance de la poésie à se rapprocher de la langue parlée. Le rejet des licences poétiques, la mise en place d'un flot continu de la parole en ont en même temps actualisé une autre composante, l'image. [...] De nouvelles possibilités de relations sémantiques sur le plan des images sont devenues, en commençant par l'œuvre de Wolker, un des éléments constitutifs de la structure de la poésie contemporaine. ${ }^{7}$

En effet, dès 1912, le projet d'une grande anthologie représentative de la poésie française, de Baudelaire aux poètes contemporains, avait rassemblé un collectif de traducteurs dont Karel Čapek, Viktor Dyk, Arnošt Procházka, Hanuš Jelínek ou Prokop Haškovec ${ }^{8}$. Si les circonstances ont empêché l'aboutissement du projet, certains résultats partiels des travaux ont fini par voir le jour, notamment Francouzská poesie nové doby [La poésie française moderne] rassemblant les traductions de K. Čapek (1920) et Ze současné poesie francouzské [De la poésie française contemporaine] de H. Jelínek (1925).

\footnotetext{
${ }^{6}$ J. Lehár, A. Stich, J. Janáčková, J. Holý, Česká literatura od počátků k dnešku, Praha, NLN, 2008, p. 452. «linii českého realismu a naturalismu ovlivnila věcnost Flaubertova, úsečná drsnost Maupassantova, naturalistická "nemravnost" Zolova ; dekadenti uctívali ironického Huysmanse [...] Na celou moderní českou poezii konce 19. století působilo dílo Bauadelairovo, Verlainovo a dalších "poètes maudits", prokletých básníků. » [traduit en français par K.D.]

${ }^{7}$ Déjiny české literatury IV (Jan Mukařovský dir.) Praha, Victoria Publishing, 1995, p. 184. «Na začátku této proměny stojí překlady francouzské poezie Karla Čapka. Čapek v nich integroval všechno podstatné, k čemu dospěla česká poezie ve svém vývoji od 90 . let, a tím vytvořil osnovu pro její další vývoj. Zvláště zřetelné je to $\mathrm{v}$ rovině jazykové, kde podpořil tendenci poezie $\mathrm{k}$ sblížení $\mathrm{s}$ jazykem mluveným. Toto oproštění od básnických licencí, vytváření plynulého toku jazyka zároveň aktualizovalo jinou jeho složku, složku obraznou. [...] Nové možnosti významových vztahů v rovině obrazného pojmenování se staly již v poezii Wolkrově jednou ze zakládajících složek struktury soudobé poezie. » [traduit en français par K.D.]

${ }^{8}$ Karel Čapek, Note du traducteur in Francouzská poezie nové doby, p. 275 ; Milan Blahynka, Note de l'éditeur in Karel Čapek, Francouzská poezie nové doby, p. 292.
} 


\section{Les répercussions de l'esthétique apollinairienne dans le milieu tchèque}

La nouvelle esthétique poétique promue par la jeune génération de poètes français, avec Apollinaire en tête, ne passe donc pas inaperçue dans le milieu tchèque, et n'y demeure pas sans écho. Dès avril 1913 $3^{9}$, Arnošt Procházka mentionne pour la première fois Apollinaire dans le magazine Moderní revue, dans une note accompagnée de sa traduction en prose du poème Rencontre. En janvier 1914, parait la critique d'Alcools de la plume de Karel Čapek dont la caractéristique approfondie de la poétique apollinairienne témoigne d'une lecture attentive et sensible ${ }^{10}$. Les premiers essais de traduction poétique ne se font pas attendre non plus: l'adaptation des Cloches (Alcools) par Stanislav Kostka Neumann, la traduction des poèmes Le voyageur (Alcools) et Sur les prophéties (Calligrammes) de Josef Čapek et surtout la traduction de Zone (Alcools) de Karel Čapek. Publiée pour la première fois dans la revue Červen en 1919, elle sera rééditée quelques mois plus tard sous forme de plaquette ${ }^{11}$ décorée de gravures sur linoléum de Josef Čapek, le frère du traducteur, avant d'être insérée dans l'anthologie Francouzská poezie nové doby à partir de sa deuxième édition en 1936. Les traducteurs tchèques d'Apollinaire se tournent dans un premier temps vers ses textes poétiques; sa prose et son théâtre attirent leur attention seulement à partir des années 20, où paraissent les traductions des nouvelles extraites de L'Hérésiarque et Cie (différents traducteurs dont notamment J. Zaorálek, F. X. Šalda, J. Starý) et du Poète assassiné (surtout A. Černík), ainsi que la version tchèque de La Femme assise (J. Fastrová) et des Mamelles de Tirésias (J. Seifert). Les années 20 et 30 verront se multiplier les traductions de différents poèmes d'Alcools, du Bestiaire ou le Cortège d'Orphée et de Calligrammes. (L'histoire des traductions tchèques d'Apollinaire jusqu'à 1960 est détaillée dans deux articles complémentaires de Vladimír Stupka : «Autour des traductions tchèques d'Apollinaire $»^{12}$ et $~ «$ Tableau des traductions tchèques d'Apollinaire ${ }^{13}$ ).

Aux yeux des théoriciens tchèques, Apollinaire annonce la régénération du lyrisme, signale la voie vers les sources propres de la poésie, incarne un nouveau type de poète et initie une nouvelle poésie ${ }^{14}$. Cette poésie, ivre du monde, dit Jiř́ Ježek, naît d'une alliance de l'intellect, du sentiment et des forces instinctives, réunies sous l'autorité de l'imagination ${ }^{15}$. Pour Karel Teige, théoricien principal de l'avant-garde poétique («poétiste ») des années 20, «Apollinaire est [...] l'axe de

\footnotetext{
${ }^{9}$ Toutefois, la publication ne pouvait être motivée par la parution d'Alcools, achevé d'imprimer le mois même; il s'agit en effet d'une information relative à la création de la revue hebdomadaire Poème et drame, dans laquelle Apollinaire a publié certains de ses poèmes. Voir Apollinaire známý neznámý, p. 13-14 et Vladimír Stupka, Autour des traductions tchèques d'Apollinaire, p. 72.

${ }^{10}$ Karel Čapek, Guillaume Apollinaire, Přehled, le 20 janvier 1914, ${ }^{\circ}$ 15, p. 271-272.

${ }^{11}$ Guillaume Apollinaire, Pásmo, traduit par Karel Čapek, Praha, Fr. Borový, 1919.

${ }^{12}$ Vladimír Stupka, Autour des traductions tchèques d'Apollinaire, Philologica Pragensia, 2, $\mathrm{n}^{\mathrm{o}} 3, \mathrm{p}$. 71-85.

13 Vladimír Stupka, Tableau des traductions tchèques d'Apollinaire, Sborník prací brněnské univerzity, 9, 1960, D7, p. 209-219.

${ }^{14}$ On trouve cette caractéristique par exemple chez Jiří Ježek et Karel Teige qui se servent de formulations presque identiques.

${ }^{15}$ Jiří Ježek, G. Apollinaire, Host, 3, nº 6-7, 1923-24, p. 137-142.
} 
toute la poésie moderne : son œuvre est un tournant à partir duquel nous datons une nouvelle époque de création moderne, l'époque présente où nous vivons et travaillons. » ${ }^{16} \mathrm{Sa}$ conception de la poésie en tant que «l'expression de rythmes infinis par le biais desquels les choses s'adressent à notre réceptivité et s'inscrivent dans notre sensibilité $\gg{ }^{17}$ a des conséquences bouleversantes pour la relation entre la forme et le contenu du poème : désormais, affirme Teige, il n'est plus possible de les distinguer et d'envisager leur relation mutuelle.

« La forme est ici une fonction de l'émotion poétique. Le rôle du poète est de créer, à partir de la matière fluide et illimitée que sont la sensibilité et l'intuition, une œuvre, résultat d'une vision directe de la réalité extérieure. Cette œuvre est une entité abstraite de nature spirituelle, un univers autonome pour soi, isolé du phénomène conventionnel et général, donc inévitablement une unité esthétique. [...] Le surréalisme apollinairien est la conception d'un art totalement détaché des fonctions imitatives, dont les ouvres sont des réalités artificielles autonomes forgées par l'auteur à partir des éléments de base purifiés, des constructions déterminées uniquement par le matériau et l'intention; ce sont des réalités humaines, d'origine humaine, et non des imitations et des dérivations des réalités naturelles. $»^{18}$

Vítězslav Nezval, lui-même un des poètes de la génération touchée par la nouvelle esthétique, puis poète surréaliste, admire l'«imagination saisissante » d'Apollinaire, ses images d'une originalité extrême, paradoxales à première vue, mettant en relation des éléments aussi éloignés que possible. Nezval s'enthousiasme de la liberté que le poète accorde à la phrase, devenue une unité autonome, repliée sur elle-même, et avec laquelle il construit des suites de phrases orchestrées par sa puissante fantaisie ${ }^{19}$.

Les poètes nés autour de 1900, constituant l'avant-garde poétique tchèque d'après-guerre, ont été sensibles particulièrement au charme de Zone, devenu un «poème culte ${ }^{20}$ de la génération, jouissant d'une popularité qui ne saurait certainement pas s'expliquer uniquement par les quelques motifs faisant allusion au court séjour pragois du poète. Aleš Pohorský rappelle que la publication de la traduction tchèque, intitulée Pásmo, en 1919, marque une date importante pour l'évolution de la poésie tchèque :

\footnotetext{
${ }^{16}$ Karel Teige, Guillaume Apollinaire a jeho doba, in Karel Teige, Výbor z díla I: Světa stavby a básně : Studie z dvacátých let, Praha, Československý spisovatel, 1966, p. 403. « Apollinaire je [...] osou všeho moderního básnictví: jeho dílo je mezníkem, od něhož datujeme novou éru moderní tvorby, éru př́tomnosti, v níž žijeme a pracujeme. » [traduit en français par K.D.]

${ }^{17}$ Karel Teige, Guillaume Apollinaire (k desátému výročí jeho smrti), Rozpravy Aventina, 4, no 11, 1928-29, p. 105.

${ }_{18}$ Ibidem, p. 106-107. «Forma je tu funkcí poetické emoce. Básníkovou úlohou jest učiniti z plynoucí, bezhraničné látky sensibility a intuice dílo, které, resultát přímé vise zevní reality, jest abstraktní skutečností duchovou, svéprávným světem pro sebe, isolovaným od konvenčního a všeobecného jevu, tedy nezbytně estetickým celkem. [...] Apollinairovský nadrealismus, tot' koncepce umění úplně odpoutaného od imitativních funkcí, jehož díla jsou svéprávnými estetickými a umělými realitami, vytvořenými autorem z pročištěných a základních elementů, konstrukce determinované toliko materiálem a úmyslem; skutečnosti lidské, lidského původu, nikoliv napodobeniny a odvozeniny skutečností přírodních. » [traduit en français par K.D.]

19 Vítězslav Nezval, Kubismus a kubofuturismus in Moderní básnické směry (1 ${ }^{\mathrm{e}}$ édition 1937), Praha, Československý spisovatel, 1964 p. 180-187.

${ }^{20}$ J. Lehár, A. Stich, J. Janáčková, J. Holý, Česká literatura od počátků k dnešku, Praha, NLN, 2008, p. 515 .
} 
"Cette traduction aussi bien que l'intitulé du poème choisi par le traducteur sont devenus décisifs pour la naissance de certaines œuvres poétiques tchèques conditionnant l'évolution ultérieure de la poésie tchèque au point que pásmo est devenu la désignation d'une forme poétique distincte. [...] En tchèque, au sens de ce mot se joint également celui d'une suite d'éléments qui s'enchaînent et, au sens figuré, à la différence du mot français, celui d'une succession d'images se suivant dans le temps et constituant, malgré leur grande diversité éventuelle, un ensemble uni. Pásmo ne représente pas pour autant qu'une forme poétique spécifique, basée sur un certain rythme et sur le relâchement des liens sémantiques entre les thèmes, mais plus généralement [...] une approche noétique à la réalité qui se constituait à la fin de la première décennie du siècle comme conséquence des tentatives de saisir les mutations précipitées de la société et de la civilisation. D'où l'accent mis sur l'aspect dynamique de la réalité. $»^{21}$

Selon Zdeněk Pešat, celui des différents aspects de Zone qui a séduit avant tout les jeunes poètes tchèques est la transformation de la structure poétique dont l'organisation n'est plus régie par un thème central précis et où le rôle du thème en tant que facteur principal d'organisation est affaibli. L'unité du texte est assurée par le sujet lyrique qui lui imprime son caractère de confession autobiographique $^{22}$. Toutefois, dit Pešat, «les éléments de la confession ne constituent pas non plus l'armature thématique du poème; ils entrent dans sa structure uniquement en tant que l'une des composantes les plus importantes qui prend part à la constitution du thème principal $»^{23}$. Zone en particulier, mais aussi l'esthétique apollinairienne au sens plus général, ont marqué de leur influence un certain nombre d'œuvres poétiques tchèques des années 20: l'inspiration par Apollinaire peut être décelée aussi bien dans de longs poèmes du genre de «pásmo » qu'au sein de plusieurs recueils poétiques de l'époque (J. Wolker, K. Biebl, J. Seifert, V. Nezval, Z. Kalista, A. M. Píša, F. Halas, V. Závada) ${ }^{24}$. Or, cette problématique, bien qu'extrêmement intéressante, ne fait pas l'objet du présent article. À ce sujet, on peut lire les deux études citées supra -

\footnotetext{
${ }^{21}$ Aleš Pohorský, Pásmo, in Poetika české meziválečné literatury, Praha, Československý spisovatel, 1987, p. 56. «Tento překlad i název pro báseň zvolený se staly určujícími pro zrod několika českých skladeb do té míry podmiňujících pozdější vývoj české poezie, že se pásmo stalo označením pro samostatnou básnickou formu. Francouzské slovo zone znamená, podobně jako český výraz pásmo, územně vymezený pruh země, prostor nebo oblast [...] V češtině však $\mathrm{k}$ těmto významům přidružuje ještě význam řetězce článků, pospojovaných jeden za druhým, a v přeneseném smyslu, na rozdíl od slova francouzského, i časový sled výjevů, které mohou být značně rozmanité, ale tvoří dohromady jeden celek. Pásmo však nepředstavuje jen specifickou básnickou formu, založenou na určitém rytmu, ale obecněji [...] určitý noetický př́stup ke skutečnosti, který se vymezoval na konci prvního desetiletí tohoto století $\mathrm{v}$ důsledku tehdejších pokusů postihnout překotné společenské a civilizační změny. Důraz v něm byl proto kladen na dynamickou stránku skutečnosti. » [traduit en français par K.D.]

${ }^{22}$ Zdeněk Pešat, Apollinairovo Pásmo a dvě fáze české polytematické poezie, in Struktura a smysl literárního díla, Praha, Československý spisovatel, 1966, p. 109-125.

${ }^{23}$ Ibidem., p. 116. «konfesijní prvky netvoří tematickou výztuž skladby, vstupují do její struktury jen jako jedna z nejdůležitějších složek, která spoluvytváŕí základní téma » [traduit en français par K.D.]

${ }^{24}$ Cf Zdeněk Pešat, Apollinairovo Pásmo a dvě fáze české polytematické poezie, in Struktura a smysl literárního díla, Praha, Československý spisovatel, 1966, p. 109-125.
} 
«Apollinairovo Pásmo a dvě fáze české polytematické poezie » de Zdeněk Pešat (1966) et « Pásmo » d'Aleš Pohorský (1987).

\section{Les traductions tchèques de Zone}

De nombreux poèmes d'Apollinaire ont fait, au cours du temps, l'objet de tentatives répétées de traduction, y compris ceux qui avaient été traduits par Čapek (c'est-à-dire Les cloches, Le voyageur, Rhénane d'automne), alors que sa traduction de Zone (Pásmo) est longtemps restée sans concurrence, sans doute du fait de son prestige aussi bien que de sa qualité. On peut d'ailleurs la lire aujourd'hui, presque un siècle plus tard, sans avoir le sentiment d'avoir affaire à un texte sensiblement vieilli, et encore moins dépassé. De nouvelles versions tchèques du célèbre poème n'ont émergé qu'au dernier quart du $20^{\mathrm{e}}$ siècle et au début du $21^{\mathrm{e}}$ siècle. Il s'agit de celles de Petr Kopta (1978), Karel Sýs (1982), Anděla Janoušková (1997), Gustav Francl (2006) et Petr Skarlant (2011).

Du vivant de Karel Ćapek, le texte de Pásmo a cependant connu quelques péripéties. En 1929, la version de Čapek s'est vue reprise et modifiée («corrigée ») par un autre traducteur d'Apollinaire, Miloš Hlávka. En 1936, Čapek a lui-même révisé sa traduction en vue de sa nouvelle publication.

\subsection{La version de Čapek « corrigée » par Hlávka}

En 1929, les poésies d'Apollinaire en traduction tchèque paraissent pour la première fois en volume sous le titre Básně Guillaumea Apollinairea ${ }^{25}$. Il s'agit d'un choix de 17 textes provenant des recueils L'enchanteur pourrissant, Alcools et Calligrammes, auxquels est joint le poème La mort de Guillaume Apollinaire de Tristan Tzara. Les textes ont été choisis, traduits et accompagnés d'une préface par Miloš Hlávka ${ }^{26}$. La seule traduction qui ne lui soit pas due est celle de Zone Hlávka a repris la traduction de Karel Čapek, qui faisait autorité dans le milieu tchèque. En revanche, il a pris la liberté d'y effectuer un certain nombre de changements. La note de bas de page indique: «Traduction de K. Čapek reproduite avec de petites modifications ${ }^{27}$. Il s'agit de la seule indication trouvable dans le recueil ; dans sa préface, Hlávka n'en dit pas un mot, pas plus qu'il n'explique sa motivation. Parler de «petites modifications » semble minimiser l'importance de celles-ci mais laisse en même temps planer le doute: quelles sont les formulations originales de Čapek et quels sont les changements dus à Hlávka ? En quoi consistent-ils ? Hlávka en avait-il le droit ? ${ }^{28}$

\footnotetext{
${ }^{25}$ Básně Guillaumea Apollinairea, Praha, Aventinum, 1929.

${ }^{26}$ Miloš Hlávka (1907-1945), écrivain, traducteur, rédacteur d'édition.

${ }^{27}$ Básně Guillaumea Apollinairea, Praha, Aventinum, 1929, p. 27. «Překlad K. Čapka přetištěný s malými změnami » [traduit en français par K.D.]

${ }^{28} \mathrm{Qu}$ 'un traducteur prenne pour point de départ la traduction d'un autre afin de proposer une nouvelle version n'est pas choquant en soi. Rappelons à ce sujet que Čapek a lui-même procédé de cette façon en traduisant les poèmes Le bateau ivre et Les chercheuses de poux de J.-A. Rimbaud, en prenant appui sur la traduction antérieure de S. K. Neumann. Or dans ce cas il est évident que l'ambition de Čapek n'était pas de corriger le texte de Neumann mais de traduire nouvellement les poèmes en s'inspirant de certaines solutions de celui-ci. Cf. Kateřina Drsková, À propos des -102 -
} 
À l'époque actuelle, un procédé pareil donnerait très certainement lieu à des poursuites judiciaires au nom des droits d'auteur et du droit à la propriété intellectuelle ; à l'époque, Hlávka s'est surtout exposé aux attaques de la critique. En réponse, Hlávka se défend en déclarant avoir obtenu de la part de Čapek l'autorisation de reproduire sa traduction ${ }^{29}$. Il est cependant douteux qu'il ait eu également sa permission de modifier son texte de quelque façon que ce soit. Certains des critiques ont été scandalisés par le fait qu'il ait osé y toucher. Jiří Mašek déplore la «retouche malheureuse de la traduction exemplaire et définitive de Čapek ${ }^{30}$ et s'indigne d'un tel «gâchis » ${ }^{31}$. Au jugement de Karel Teige Hlávka aurait «profané la mémoire du grand poète » et remanié la traduction de Čapek «de manière ridicule $»^{32}$. La justification de Hlávka paraît assez naïve : «[...] je'n ai pas traité la traduction de Čapek avec un tel arbitraire. En effet, je n'ai corrigé qu'une erreur que Čapek avait commise [...] et certains passages où je ne pouvais être d'accord avec sa méthode $»^{33}$. Hlávka semble ne pas réaliser le caractère problématique de sa démarche, il ne reconnaît qu'une erreur corrigée (il y en a eu davantage) et quant aux solutions désapprouvées, il cite seulement l'exemple de la fin du poème, traduite effectivement par Čapek d'une manière moins satisfaisante. On peut pourtant constater que Hlávka est intervenu sur une soixantaine de vers du poème ! Naïveté réelle ou feinte ? Du fait de sa jeunesse - il n'avait que 21 ans - et donc de son peu d'expérience il est plutôt à croire qu'il était sincèrement persuadé de bien faire.

$\mathrm{Si}$ nous laissons de côté les modifications de l'orthographe (par ex. próza/prosa, Nizza/Nice, Gouda/Guda) - sans véritable signifiance et d'ailleurs peu nombreuses - nous pouvons constater plusieurs types de retouches. Dans certains cas, Hlávka a corrigé ce qu'il devait considérer comme erreurs ou méprises, notamment les deux suivantes (bien que le premier exemple soit discutable) :

original : «[...] la double potence de l'honneur et de l'éternité » (v. 37)

version de Čapek : «[...] dvojmocnina cti a věčnosti » ([...] le nombre carré de l'honneur et de l'éternité)

version de Hlávka : «[...] dvojramenná šibenice cti a věčnosti » (la potence à deux bras de l'honneur et de l'éternité)

original : «[...] un édredon rouge $[\ldots] \gg(\mathrm{v} .128)$

version de Čapek : «[...] praporek červený » ([...] le drapeau rouge)

version de Hlávka : « [...] červenou peřinu » (traduction littérale)

\footnotetext{
traductions tchèques du Bateau ivre de Jean-Arthur Rimbaud, Écho des études romanes, VII, $n^{\circ} 2$, 2011, p. 31-44.

${ }^{29}$ Miloš Hlávka, Kritika tvưrčí a vědecká, Rozpravy Aventina, 4, no 39-40, 1928-29, p. 395.

${ }^{30}$ Jiří Mašek, G. Apollinaire: Básně, Literární noviny, 3, č. 11, 30.5.1929, s. 3. «Nešt’astná úprava vzorného a definitivního Čapkova překladu » [traduit en français par K.D.]

${ }^{31}$ Jiří Mašek, Chyba lávky - Chyba Hlávky!, Literární noviny, 3, č. 18, 17.10.1929, s. 3. «zbabrání

Čapkova překladu Pásma » [traduit en français par K.D.]

32 [Karel Teige], Guillaume Apollinaire : Básně, ReD, 2, nº 8, 1928-29, p. 267.

${ }^{33}$ Ibidem.
} 
Si toutefois Hlávka voulait corriger ce type d'imperfections, pourquoi en avoir laissé passer d'autres ? Par exemple dans le vers «Et d'Amérique vient le petit colibri » (v. 60), Čapek traduit «A z Ameriky došel malý kolibř́k ». Le verbe tchèque dojít (došel est la $3^{\mathrm{e}}$ personne du singulier du passé) n'est que partiellement équivalent au verbe français venir, il a un sens plus restreint et ne désigne que le mouvement effectué à pied. L'équivalent contextuel de venir serait doletět ou přiletět. Ici, il ne s'agit certes pas d'une vraie erreur, plutôt d'une maladresse. Hlávka n’a pas non plus redressé le défaut dans le vers 99: «La cétoine qui dort dans le cœur de la rose», que Čapek traduit: «Hledě na mandelinku spící v růžovém kalichu ». Or mandelinka n'est pas la cétoine, qui se dit zlatohlávek en tchèque, mais la chrysomèle. Confondre les deux coléoptères a d'abord une conséquence pour l'esthétique de l'image: le mot mandelinka est certes joli et poétique, aussi bien que zlatohlávek, mais ce n'est pas a priori valable pour l'insecte lui-même. Il existe beaucoup d'espèces de chrysomèle, d'aspects variés, mais celle qui est bien connue des néophytes même (et à laquelle le mot risque probablement de faire penser le lecteur, c'est-à-dire le doryphore) est peu attractive, rayée de jaune et de brun, alors que la cétoine brille de beaux reflets dorés (ce que son nom tchèque évoque même pour un non-spécialiste). Ensuite, c'est trahir la facette réaliste du texte d'Apollinaire qui se traduit ici par un détail botanique et entomologique précis: la cétoine (appelée aussi pour cause « hanneton des roses $»^{34}$ ) se nourrit avec prédilection de fleurs de $\operatorname{rosier}^{35}$, alors que la chrysomèle en question ravage les cultures de pomme de terre. (Comment se fait-il que Čapek, un jardinier fervent, n'y ait pas été attentif ?) En se risquant un peu plus loin encore, on pourrait même considérer que cette image représente une variation originale du motif cher aux poètes de la Renaissance - la cétoine dormante représente une menace potentielle pour la rose et rappelle ainsi la précarité de l'existence, à l'instant même où le poète est en train de vivre un moment de bonheur. La présence d'une chrysomèle ne produit pas le même effet.

D'autres modifications effectuées par Hlávka consistent à ramener de manière pédantesque à une traduction fidèle des passages dans lesquels la traduction de Čapek s'écarte un peu du sens de l'original (ce qui arrive généralement dans l'intérêt de la rime ou de la cadence du vers), soit par léger glissement de sens (les deux premiers exemples), soit par omission ou ajout d'un élément (les deux derniers exemples) :

original : «Une cloche rageuse y aboie vers midi » (v. 20)

version de Čapek: «Chraptivý zvon zde zaštěká k poledni » (Une cloche roque y aboie vers midi)

version de Hlávka : «Vzteklý zvon zde zaštěká k poledni » (traduction littérale)

original : «Entourée de flammes ferventes Notre-Dame m'a regardé à Chartres » (v. 83)

version de Čapek: «Z koruny žhavých plamenů požrela na mne Panna v Chartres » (Entourée d'une couronne de flammes ardentes la Vierge m'a regardé à Chartres )

version de Hlávka: «Ze žhoucích plamenů pohlédla na mne Panna Maria v Chartres » (traduction littérale)

\footnotetext{
${ }^{34}$ https://fr.wikipedia.org/wiki/C\%C3\%A9toine_dor\%C3\%A9e [cité le 4 août 2015].

${ }^{35}$ Ibidem.
} 
original : «Du lundi matin au samedi soir quatre fois par jour y passent » (v. 18)

version de Čapek: «Z $\mathbf{Z}$ pondělí do soboty čtyřikrát denně tudy se berou » (Du lundi au samedi quatre fois par jour y passent)

version de Hlávka : «Od pondělního rána do sobotního večera čtyřikrát denně se tudy berou » (traduction littérale)

original : «Icare Enoch Elie Apollonius de Thyane// Flottent autour du premier aéroplane » (v. 49-50)

version de Čapek : «Ikarus Enoch Eliáš Apollonius z Thyany // Kol prvního letadla krouží u nebeské brány » (Icare Enoch Elie Apollonius de Thyane // Tournoient autour du premier aéroplane à la porte du ciel)

version de Hlávka: «Enoch Eliáš Apollonius z Thyany i Ikaros sám // Obletují první aeroplán » (traduction littérale, changement uniquement dans l'ordre des noms afin de garder la rime)

Dans le même esprit, Hlávka remplace par la sienne la solution trouvée par Čapek pour traduire le dernier vers du poème. «J'ai préféré la métaphore originale à l'imitation de la mélodie de l'original dans la traduction de Čapek ${ }^{36}$, justifiera Hávka par la suite.

original : «Adie Adieu // Soleil cou coupé » (v. 156-157)

version de Čapek : «Sbohem sbohem spáči // Slunce plá pláče » (Adieu adieu dormeur // Le soleil flambe pleure)

version de Hlávka : «Sbohem sbohem // Slunce hrdlo přetaté » (Adie adieu // Soleil gorge coupée)

Le pédantisme de l'adaptateur se manifeste aussi dans le fait d'avoir ajouté la marque du pluriel au mot français bureau que Čapek emploie au singulier pour traduire le vers «Les directeurs les ouvriers et les belles sténo-dactylographes » et pour le lier par la rime avec le vers suivant. Si Čapek traduit les «sténodactylographes » par «písařky z bureau » (les sténo-dactylographes du bureau), Hlávka poussant la logique jusqu'au bout met le mot au pluriel : «písařky z bureaux » (les sténo-dactylographes des bureaux) - car s'il y a plusieurs sténodactylographes, il doit y avoir aussi plusieurs bureaux.

On peut enfin constater un certain nombre de changements qui semblent arbitraires: un mot ou une expression remplacé/e par un/e autre, parfois pleinement synonyme (les deux premiers exemples) ou du moins d'un sens très proche :

original : «J'ai vu ce matin une jolie rue dont j'ai oublié le nom » (v. 15)

version de Čapek : «Viděl jsem dnes a jméno už nevím pěknou ulici »

version de Hlávka : «Viděl jsem dnes ráno hezkou ulici nevím už jméno »

original : «L'avion se pose enfin [...]» (v. 53)

version de Čapek : «Avion [...] se snáší a klesá »

version de Hlávka : «Letadlo [...] se vznáší a klesá »

\footnotetext{
${ }^{36}$ Miloš Hlávka, Kritika tvưrčí a vědecká, Rozpravy Aventina, 4, č. 39-40, 1928-29, s. 395. « Mně byla milejší metafora originálu než melodické připodobnění Čapkova překladu k originálu. »
} 
original : « [...] les femmes sont ensanglantées » (v. 81)

version de Čapek : «[...] ženy jsou krví znamenány » (les femmes sont marquées de sang)

version de Hlávka : «[...] ženy jsou krví postř́kány » (les femmes sont éclaboussées de sang)

original : «Et tu bois cet alcool brûlant comme ta vie » (v. 150)

version de Čapek : «A ty piješ ten líh palčivý jako života bol » (Et tu bois cet alcool brûlant comme la douleur de ta vie)

version de Hlávka : «A ty piješ tu palčivou kořalku jako života bol » (Et tu bois cette eaude-vie brûlante comme la douleur de ta vie)

Résumons: certaines des modifications de Hlávka pourraient sembler judicieuses, mais à la seule condition de les isoler du texte et de faire abstraction de la conception selon laquelle celui-ci a été traduit par Čapek. Or, ne pouvant être dissociées de ce contexte, elles se montrent pour la plupart inacceptables ou du moins injustifiées, arbitraires. Hlávka est intervenu dans le texte sans tenir compte du contexte immédiat, sans être sensible à la cadence du vers, au jeu subtil des sonorités, aux sens figurés. Ses retouches, bien que souvent pédantesques, ne sont pas systématiques, et qui plus est, il lui arrive de reproduire à un autre endroit le même type d'erreur qu'il corrige ailleurs. Sans le comprendre, il a bousculé la construction fragile mais équilibrée de la traduction de Čapek. L'approche de Hlávka offre maints exemples du fait que la traduction fidèle dans le sens du mot à mot trahit souvent l'original bien davantage qu'une traduction à l'apparence plus libre. On ne peut qu'être d'accord avec la critique de Mašek (quoique son ton soit bien trop agressif) : la retouche de Hlávka semble somme toute malheureuse ${ }^{37}$.

\subsection{Deux versions de la traduction de Čapek}

La courte période pendant laquelle Karel Čapek s'est consacré intensivement à la traduction se termine en 1921. Il n'y revient qu'en 1936 pour préparer une deuxième édition revue et augmentée de son anthologie des traductions de la poésie française (sous un titre modifié Francouzská poesie). D’une part, il révise ses traductions antérieures, d'autre part, il ajoute de nouvelles traductions pour enrichir le panorama de la poésie française moderne ainsi présentée. De ce fait il est amené à revoir également sa traduction de Zone de $1919^{38}$ qui est destinée à

\footnotetext{
${ }^{37}$ Les critiques se sont montrés hostiles non seulement aux modifications que Hlávka a apporté à la version de Čapek, mais aussi à son choix de poèmes d'Apollinaire qui ne leur paraissait par représentatif (Václav Černý), ainsi qu'à sa méthode de traduction (Karel Teige, Jiří Mašek). Teige trouve les traductions de Hlávka peu réussies, sans précision, rendant mal l'original, Mašek se moque ouvertement des connaissances philologiques insuffisantes du traducteur. Quant à Černý, qui ne trouve rien de grave à reprocher à la traduction sur le plan linguistique, il conclut cependant son compte-rendu en constatant que le traducteur manque totalement de sensibilité pour les qualités musicales de la langue d'Apollinaire.

À notre connaissance, il n'y a pas eu de réaction publique de la part de Čapek; sa correspondance publiée ne porte non plus aucune trace de cette affaire (peut-être ne voulait-il pas s'impliquer dans la polémique devenue assez violente; peut-être, faisant le deuil de son père, trouvait-il la cause marginale).

${ }^{38}$ Entre temps, cette première version de Pásmo a été reprise aussi dans le cadre d'une anthologie rassemblant les traductions apollinairiennes de plusieurs traducteurs tchèques, dont Karel Čapek. Le volume intitulé simplement Básně, s'ouvrant par la préface de Karel Teige, a paru en 1935.
} 
intégrer nouvellement l'anthologie ${ }^{39}$. De quelle nature sont les changements effectués par Čapek lors de la révision du texte ? S'agit-il de modifications significatives ou seulement de retouches de surface ? Dans sa note, le traducteur affirme avoir «laissé le fruit de [s]on travail de traduction tel quel, excepté quelques retouches et ajouts $»^{40}$. Or dans l'édition de 1957 , la note de l'éditeur indique, sans toutefois donner d'exemples concrets, que les modifications ont été plus nombreuses et plus importantes que la note du traducteur ne le laisse entendre. Ces modifications sont signalées également par Vladimír Stupka qui considère que la révision du texte a «permis de préciser l'image poétique d'Apollinaire et par des variantes heureuses de se rapprocher d'autant plus de la poésie originale. ${ }^{41}$ Hélas, Stupka se limite lui aussi à un constat général sans le développer davantage et sans citer d'exemples à l'appui de sa thèse.

La confrontation des deux versions tchèques nous permet de vérifier que la version de 1936 a connu effectivement un certain nombre d'interventions. Il s'agit d'une vingtaine de modifications de nature et d'importance diverses, mais toutes significatives de la méthode de Čapek que résume la citation suivante :

«Cherchant à transposer fidèlement l'original, Čapek a eu recours à la langue parlée ; l'utilisation de celle-ci a débouché sur la réorganisation de la structure entière du vers, du lexique, de la structure phrastique (notamment le rejet de l'inversion), du rythme et de l'intonation [...], de la rime (usage abondant de l'assonance). ${ }^{42}$

Certaines des modifications en question sont motivées par la recherche d'une plus grande fidélité à l'original, comme le montrent les exemples suivants : v. 13)

original : «Il y a les livraisons à 25 centimes pleines d'aventures policières » (Zone,

version 1919: «Sešity po šestáku o detektivech kteří prosluli » (Les livraisons à 25 centimes sur les détectives qui sont devenus célèbres)

version 1936 : «Jsou krváky po šestáku samé detektivní případy » (Il y a les romans noirs à 25 centimes que des aventures policières)

original : «L'avion se pose enfin sans refermer les ailes » (Zone, v. 53)

version 1919 : «Avion s kř́ídly nesloženými snáší se a klesá » (L'avion aux ailes dépliées descend et se pose)

version 1936 : «Avion snáší se posléz aniž křídla složil » (L'avion se pose enfin sans refermer les ailes)

Par contre toutes les éditions suivantes de Francouzská poesie (nové doby) se baseront sur celle de 1936 et reproduiront ainsi la version corrigée de Pásmo.

${ }^{39}$ D'après la note de l'éditeur in Karel Čapek, Francouzská poezie nové doby, Čs. spis., 1964, p. 292-295.

${ }_{40}$ «ponechávám toto své překladatelské klasobraní tak, jak bylo, až na několik oprav a doplňků ». Note du traducteur reproduite dans l'édition de 1957, p. 275. [traduit en français par K.D.]

${ }^{41}$ Vladimír Stupka, Autour des traductions tchèques d'Apollinaire, Philologica pragensia, $2, \mathrm{n}^{\mathrm{o}} 3$, Praha, Nakladatelství ČSAV, 1960, p. 73.

${ }^{42}$ Jan Mukařovský (dir.), Dějiny české literatury IV, Praha, Victoria Publishing, 1995, p. 588. «Ve snaze o přesné postižení originálu sáhl Čapek k mluvenému jazyku; jeho využití vedlo k přestavbě celé veršové struktury, slovníku, větné stavby (zejména opuštění inverze), rytmicko-intonační organizace [...] rýmu (bohaté využití asonance). » [traduit en français par K.D.] 
original : «L'oiseau Roc célébré par les conteurs et les poètes » (Zone, v. 57)

version 1919 : «Pták Noh jemuž básně a pohádky hlásají slávu » (L'oiseau Roc dont les poèmes et les contes chantent la gloire)

version 1936 : «Pták Noh jejž básníci a pohádkáři slaví » (L'oiseau Roc que célèbrent les conteurs et les poètes)

Jiří Levý constate que la traduction tendant à suivre l'original de très près est caractéristique de la méthode de Čapek, au risque de donner parfois lieu à des «primitivismes » pouvant mettre en doute sa propre compréhension du texte original $^{43}$. Un tel exemple peut être trouvé aussi dans sa traduction de Zone. Dans le vers 6, « les hangars de Port-Aviation » est traduit par Čapek d'abord comme « hangáry na letišti » (les hangars de l'aéroport). Dans la deuxième version de sa traduction, il a recours à une autre solution : «hangáry v př́stavu avionů » (les hangars du port des avions). À la première vue, cette traduction littérale semble servile et fautive - l'expression «přístav avionů »n'existe pas en tchèque. Čapek ne pouvait pas ne pas en être conscient. Cependant, Milan Blahynka, s'appuyant sur un exemple concret tiré du poème Les Cloches (Zvony en tchèque), propose une explication de tels cas, fréquents dans les traductions de Čapek. Selon lui, la solution est «fautive du point de vue de la langue, mais par la voie de cette incorrection est née une image poétique nouvelle, extraordinairement explicite. [...] Il est possible de l'interpréter ainsi : il ne s'agit pas d'une inadvertance mais de l'imitation consciente d'une expression française $[\ldots] »{ }^{44}$.

D'autres modifications, concernant l'ordre des mots et par conséquent l'intonation, rendent l'expression plus naturelle et la rapprochent de la langue parlée :

original : «Comme si tu ne devais jamais plus être aimé » (Zone, v. 74)

version 1919 : «Jako bys už nikdy se neměl lásky dočkati »

version 1936 : «Jako bys nikdy už se neměl lásky dočkati »

original : «Vous avez honte quand vous vous surprenez à dire une prière » (Zone, v. 76)

version 1919: «Když na rtech si najdete modlitby vy rdíte do ruda se »

version 1936 : «Rdíte se studem když se sami chytnete při modlení »

original : «J'ai une pitié immense pour les coutures de son ventre » (Zone, v. 142)

version 1919: «Mám soustrast nesmírnou se švy jejího břicha »

version 1936 : « Mám nesmírnou soustrast se švy jejího břicha »

On peut enfin identifier des modifications d'ordre lexical qui remplacent des mots ou des expressions littéraires par des équivalents plus courants, familiers et parfois plus expressifs. Ainsi, «les livraisons à 25 centimes » (v. 13), traduit

\footnotetext{
${ }^{43}$ Jiří Levý, Čapkovy překlady ve vývoji českého překladatelství a českého verše, in Bude literární věda exaktní vědou? Výbor studií, Praha, Československý spisovatel, 1971, p. 239. " primitivismy hraničící až s neporozuměním » [traduit en français par K.D.]

${ }^{44}$ Milan Blahynka, Sedm odstavců k Čapkově Francouzské poezii, in Karel Čapek, Francouzská poezie nové doby, Praha, Československý spisovatel, 1957, p. 283. «[překlad je] jazykově nesprávný, ale cestou této nesprávnosti se zrodil nový básnický obraz, neobyčejně názorný [...] Dá se to vyložit tak: nejde o nedopatření, jde o vědomou nápodobu francouzského rčení [...] ». » [traduit en français par K.D.]
} 
d'abord par «sešity po šestáku », devient «krváky po šestáku »; «jsem chor » («je suis malade», v. 85) change en «jsem z toho nemocen»; la version primitive de la traduction du vers «Et revenir dans leur pays après avoir fait fortune » (v. 126) - «A domů se vrátí nesouce s sebou tisíce » - est maintenant remplacée par «A že se vrátí domů až nadělají jmění », plus familier en même temps que plus littérale.

Dans certains cas, ces modifications entraînent des changements secondaires au niveau des sonorités, notamment en ce qui concerne celles de fin de vers. La solution consiste alors à créer une nouvelle rime ou une assonance qui remplace la variante primitive, parfois facile (zpívají/dávají, tř̌́šti/letišti) :

version 1919 :

version 1936 :

« Jen náboženství zůstalo nové ve starých věcí tříšsti

Zůstalo zcela prosté jak hangary na letišti »

(Pásmo, v. 5-6)

« Jen náboženství zůstalo docela nové jenom ono

Zůstalo prosté jak hangáry v př́ístavu avionů »

« Čteš letáky cenníky plakáty jež nahlas zpívají

Tot' poesie dne a prózu dne žurnály dávají

Sešity po šestáku o detektivech kteří prosluli

Portréty slavných mužů a steré tituly »

(Pásmo, v. 11-14)

« Čteš letáky cenníky plakáty jež zpívají hlasitě

Tot' dnešní poezie zatímco prózou žurnály sytí tě

Jsou krváky po šestáku samé detektivní případy

Portréty velkých osob a sterá různá záhlaví »

« Tot' obraz visící v temnu galerie

A vidět jej zblízka ti třeba chvílemi je »

(Pásmo, v. 79-80)

« Tot’obraz visící ve stínu muzea

A občas přijdu na něj se zblízka podívat »

Jiří Levý affirme que «Karel Čapek a libéré non seulement l'organisation rythmique du vers tchèque mais aussi la rime tchèque; ses traductions ont été à la naissance de la soi-disant rime décanonisée de la poésie moderne ${ }^{45}$. Les rimes de Čapek contrastent vivement avec la norme de la versification traditionnelle : elles peuvent dépasser la limite du mot, être basées sur une identité imparfaite des sons ou céder la place à l'assonance. Comme l'explique Levý, c'est la conséquence

\footnotetext{
${ }^{45}$ Jiří Levý, Čapkovy překlady ve vývoji českého překladatelství a českého verše, in Bude literární věda exaktní védou? Výbor studií, Praha, Československý spisovatel, 1971, p. 249. «Karel Čapek uvolnil nejen rytmickou organizaci českého verše, ale také český rým; jeho překlady stály u kolébky tzv. dekanonizovaného rýmu moderní poezie » [traduit en français par K.D.]
} 
d'une conception de la rime qui soumet celle-ci à l'ordre rythmique du vers ${ }^{46}$ : « chez Čapek la rime n'est pas une identité des syllabes finales isolées mais la fin, strictement organisée et soulignée par la cadence, de l'ossature sonore du vers, composée de voyelles. [...] La rime par ses assonances est en relation avec les harmonies sonores internes du vers où les voyelles se trouvent fortement mises en relief $»^{47}$.

Toutes ces retouches ne sont censées que perfectionner la traduction dans le détail, de la parachever selon les principes de la méthode de Čapek. La seule modification qui puisse être considérée comme substantielle a été effectuée au niveau des derniers vers du poème. En ce qui les concerne, Čapek a reconsidéré sérieusement sa première solution de traduction :

original :

« Adieu adieu

Soleil cou coupé » version 1919 :

«Sbohem sbohem spáči $\rightarrow$

Slunce plá pláče »

(littéralement :

Adieu adieu dormeur

Le soleil flambe pleure) version 1936 :

«Sbohem sbohem jsi ospalý

Slunce ut'atá hlava

Se kuku kutálí »

(littéralement :

Adieu adieu tu as sommeil

Le soleil la tête coupée

Rourou roule)

Dans le cas des deux derniers vers du poème, le traducteur tchèque se heurte inévitablement à l'impossibilité d'une traduction fidèle à tout égard - les traductions plus récentes de Kopta, Sýs, Francl et Skarlant le confirment d'ailleurs à l'unisson. Dans la première version de sa traduction, Čapek s'est focalisé d'avantage sur la forme que sur le fond, en cherchant à reproduire l'effet sonore de l'original et même à l'amplifier. Il y est parvenu par l'ajout du motif du sommeil (spáči) inspiré par les vers précédents ([...] tu vas aller chez toi à pied // dormir [...]) et par la création de l'écho plá pláče, analogue à l'original. Cela faisant, il a pris l'initiative de renforcer l'effet de la paronomase par la rime (spáči/pláče), quoiqu'imparfaite et nullement motivée par l'original. La solution produit certes son effet sonore mais au prix d'un glissement sémantique sensible (Slunce plá pláče $)$ et de la disparition de la métaphore finale soleil $\approx$ cou coupé, image crue et d'une grande force, chargée de sens. Par ces concessions Čapek déroge exceptionnellement à son principe de traduction aussi littérale que possible (ce qui dans son cas ne veut pas pour autant dire servile) qui le lie avec la génération des traducteurs de la fin du $19^{\mathrm{e}}$ siècle et dont la génération suivante se détourne ${ }^{48}$ (de

\footnotetext{
${ }^{46}$ Jiří Levý, Čapkovy překlady ve vývoji českého překladatelství a českého verše, in Bude literární věda exaktní vědou? Výbor studií, Praha, Československý spisovatel, 1971, p. 249.

${ }^{47}$ Jiří Levý, Čapkovy překlady ve vývoji českého překladatelství a českého verše, in Bude literární věda exaktní vědou? Výbor studií, Praha, Československý spisovatel, 1971, p. 252. « rým u Čapka není shoda izolovaných koncových slabik, ale přísněji organizovaný a kadencí podtržený konec samohláskové kostry verše. [...] Rým svými asonancemi souvisí s vnitřními zvukosledy Čapkova verše, v němž samohlásky jsou silně zvukově exponovány ». [traduit en français par K.D.]

${ }^{48}$ Cf. Jiří Levý, České theorie prekladu, Praha, SNKLHU, 1957.
} 
telles licences seront monnaie courante par exemple dans les traductions poétiques de Vítězslav Nezval).

La nouvelle version de la fin du poème témoigne du fait que cette fois, Čapek a tenté de conjuguer les deux exigences - celle de la forme et celle du sens. Si un glissement sémantique n'a pu être évité, il est moins important comparé à la première version : à part l'ajout du motif du sommeil qui est reproduit par d'autres mots (jsi ospalý), il consiste à doter l'image finale, maintenue cette fois, de dynamisme par un verbe de mouvement (Slunce utatá hlava // se kuku kutálí). Ce glissement est justifié par le fait qu'il permet la reproduction des sonorités de l'original ; Čapek a même trouvé moyen d'utiliser la même syllabe [ku] (cou coupé - kuku kutálí), bien que par le truchement d'un jeu de mots quelque peu dadaïste qui n'a pas réellement d'appui dans la poétique apollinairienne. Or il faut souligner le fait qu'il s'agit d'un problème extrêmement difficile à résoudre - il n'y a pas de solution idéale par rapport à l'original, le traducteur ne peut qu'essayer de s'en rapprocher au moyen de compromis plus ou moins satisfaisants.

Si Čapek a pris soin de revoir et de corriger partiellement sa traduction de Zone de 1919, il est d'autant plus surprenant qu'il n'ait pas éliminé certaines imperfections ponctuelles qui relèvent d'imprécisions voire d'erreurs. On peut rappeler les cas déjà cités au sous-chapitre 3.1. ou encore le vers «Ses mains que je n'avais pas vues sont dures et gercées » (v. 141), traduit d'abord de manière un peu illogique « Neznám její ruce jsou tvrdé a rozprýskané » (Je ne connais pas ses mains elles sont dures et gercées), qui a été modifié sans que la contradiction disparaisse, la nouvelle version étant «Nevím jaké má ruce jsou tvrdé a rozprýskané » (Je ne sais pas comment sont ses mains elles sont dures et gercées). Ces cas sont cependant peu nombreux et ponctuels et ne compromettent pas sérieusement la qualité de l'ensemble de la traduction.

\section{En guise de conclusion}

La traduction de Čapek reste jusqu'à nos jours la version tchèque la plus connue du célèbre poème, et demeure toujours d'actualité (la première édition de 1919 a fait l'objet de deux réimpressions en 1997 et $2005^{49}$ ). Il existe cependant cinq autres traductions plus récentes : celle de Petr Kopta $(1978)^{50}$, Karel Sýs $(1982)^{51}$, Anděla Janoušková $(1997)^{52}$, Gustav Francl $(2006)^{53}$ et Petr Skarlant $(2011)^{54}$. Les traducteurs ont dû nécessairement tenir compte de l'existence de la version incontournable de Čapek et bien qu'ils aient cherché chacun une approche

\footnotetext{
${ }^{49}$ Guillaume Apollinaire, Pásmo, Praha, Protis, 1997, 2005.

${ }^{50}$ Guillaume Apollinaire, Pásmo, Praha, Martin Dyrynk, 1978.

${ }^{51}$ Guillaume Apollinaire, Pásmo, Praha, Supraphon, 1982.

52 Guillaume Apollinaire, Pásmo, [Olomouc], Olomoucká skupina členů Spolku českých bibliofilů, 1997.

${ }^{53}$ In Guillaume Apollinaire, Alkoholy, V Praze, Vyšehrad, 2005.

${ }^{54}$ Guillaume Apollinaire, Pásmo, V Praze, KGB, 2001.
} 
individuelle, indépendamment des solutions de Čapek, ils lui ont tous emprunté le titre qu'il avait trouvé : Pásmo ${ }^{55}$.

L'autorité dont bénéficie la traduction de Čapek se confirme aussi de manière indirecte par le fait que les traducteurs récents n'ont généralement pas destiné leur version à une large distribution mais à un cercle restreint de lecteurs (du moins lors de la première parution). À part celle de Gustav Francl, les quatre autres traductions ont fait l'objet d'éditions destinées aux bibliophiles tirées à un petit nombre d'exemplaires, hors commerce dans certains cas. Seules les traductions de Kopta et Sýs ont été reprises plus tard dans le cadre des publications standard. De ce fait, l'impact de ces traductions est limité, certaines d'entre elles demeurant pratiquement inconnues et inaccessibles (Janoušková, Skarlant).

\section{Traductions tchèques de Zone $1978-2011^{56}$}

\begin{tabular}{|l|l|l|l|l|}
\hline Traducteur & $\begin{array}{l}\text { Première } \\
\text { parution }\end{array}$ & $\begin{array}{l}\text { Nombre } \\
\text { d'exemplaires }\end{array}$ & $\begin{array}{l}\text { Édition } \\
\text { bibliophile }\end{array}$ & $\begin{array}{l}\text { D'autres éditions } \\
\text { que bibliophiles }\end{array}$ \\
\hline Petr Kopta & 1978 & 35 & oui & oui \\
\hline Karel Sýs & 1982 & $?$ & oui & oui \\
\hline $\begin{array}{l}\text { Anděla } \\
\text { Janoušková }\end{array}$ & 1997 & 150 & oui & non \\
\hline Gustav Francl & 2006 & $?$ & non & oui \\
\hline Petr Skarlant & 2011 & 100 & oui & non \\
\hline
\end{tabular}

Comment expliquer le fait que Karel Čapek a endossé son rôle de traducteur avec un tel bonheur? Jan Mukařovský suppose que sa réussite est due à sa qualité d'écrivain prosateur (bien que ses débuts littéraires soient liés à la poésie) : n'étant pas déterminé par un style poétique propre, il était en mesure de se mettre entièrement au service du poète traduit ${ }^{57}$. À cela s'ajoute la conception de traduction à laquelle Čapek adhère : Mukařovský le classe parmi les traducteurs cherchant à transposer la structure poétique étrangère de manière aussi précise que possible et rappelle que Čapek, en définissant la tâche du traducteur dans la préface à son anthologie, déclare que son travail doit être invisible, que le traducteur est censé ne laisser aucune trace de sa personnalité dans le texte traduit $^{58}$.

\footnotetext{
${ }^{55}$ Certaines de ces traductions ont fait récemment l'objet d'analyses et de comparaisons dans le cadre des mémoires de licence et de maîtrise rédigés dans les universités tchèques :

Eva Všetulová, Komparativní pohled na české překlady Apollinairova Pásma, Olomouc, Univerzita Palackého, 2008. Mémoire de licence comparant les traductions de Čapek, Kopta et Sýs.

Eva Všetulová, Stylistické hodnocení překladu. Guillaume Apollinaire: Pásmo, Zvony, Univerzita Palackého, 2010. Mémoire de maîtrise, comparaison stylistique des traductions de Čapek, Kopta, Sýs et Francl.

Eva Cihláŕová, Překladové varianty Apollinairova Pásma, Praha, Univerzita Karlova, 2014. Mémoire de maîtrise, comparaison des traductions et méthodes de Čapek, Kopta, Sýs, Francl et Skarlant.

${ }^{56}$ Données puisées dans le catalogue collectif (SKC) de la Bibliothèque nationale tchèque.

${ }^{57}$ Jan Mukařovský, K novému vydání Francouzské poesie K. Čapka, Slovo a slovesnost, 2, ${ }^{\circ} 4$, 1936, p. 253-255.

${ }^{58}$ Ibidem.
} 
Jiří Levý pense que cette réussite pourrait s'expliquer par des analogies - des «parentés typologiques »- entre les écritures respectives des deux écrivains ${ }^{59}$. Il en identifie trois principales: "le contraste des différentes nuances du sens aboutissant jusqu'à l'union de la réalité et de l'imagination, la composition fluide où s'estompe la suite logique des éléments aussi bien que la syntaxe et le naturel ne supportant ni décoration ni pathos - voici les points communs entre les méthodes artistiques d'Apollinaire et de Čapek. ${ }^{60}$ Cette parenté aurait permis à Čapek de comprendre et de traduire la poésie d'Apollinaire mieux que d'autres traducteurs tchèques.

Enfin, c'est aussi sans aucun doute la sensibilité exceptionnelle de Čapek à l'égard de la langue tchèque et son intérêt pour la langue parlée, contemporaine, vivante, mais aussi pour la culture de la langue et pour la linguistique qui ont participé de la qualité de ses traductions. «L'enseignement puisé dans les travaux de linguistique se combinait avec son talent d'observateur qui ne se focalisait pas que sur les réalités du monde et sur la vie qui était la sienne, mais s'accompagnait aussi d'une observation attentive et d'une réflexion à propos des faits langagiers ${ }^{61}$, constate Alois Jedlička. Et il précise que Čapek était particulièrement attentif aux nuances subtiles du sens, aux connotations et aux relations entre les unités lexicales.

C'est certainement grâce à l'ensemble de toutes ces circonstances que la traduction de Zone de Karel Čapek, au sujet de laquelle Vítězslav Nezval déclare qu'elle «se lit comme un poème tchèque original ${ }^{62}$, représente le sommet, en même temps que la synthèse ${ }^{63}$, de son travail de traduction et résonne encore à l'heure actuelle dans le milieu tchèque.

\section{BIBLIOGRAPHIE}

APOLliNAIRE Guillaume (1929), Básně Guillaumea Apollinairea, Praha, Aventinum.

APOLLINAIRE Guillaume (1935), Básně, Praha, Ústřední dělnické knihkupectví a nakladatelství v Praze.

BERTHIER P.; JARRETY P. M. (dir., 2006), Histoire de la France littéraire, vol. III, Modernités, Paris, Quadrige/PUF.

\footnotetext{
${ }^{59}$ Jiří Levý, Čapkovy překlady ve vývoji českého překladatelství a českého verše, in Bude literární věda exaktní vědou? Výbor studií, Praha, Československý spisovatel, p. 227-258. Levý s'inspire d'une analyse de Jan Mukařovský portant sur l'écriture de Čapek.

${ }^{60}$ Jiří Levý, Čapkovy překlady ve vývoji českého překladatelství a českého verše, in Bude literární věda exaktní védou? Výbor studiú, Praha, Československý spisovatel, p. 229-230. "Kontrastování různých významových tónin vedoucí až ke splynutí skutečnosti a fantazie, kompoziční splývavost zastírající logický sled věcí i syntaxi a přirozenost nesnášející dekoraci ani patos - to jsou styčné body umělecké metody Apollinairovy a Čapkovy. » [traduit en français par K.D.]

${ }^{61}$ Alois Jedlička, Jazykové a jazykovědné zájmy Karla Čapka, Naše řeč, 74, 1991, p. 6-15. «K poučení, které z těchto prací čerpal, přistupoval jeho talent pozorovatelský, který se neomezoval jen na pozorování skutečností světa, který jej obklopoval, a života, kterým žil, ale byl doprovázen i vnímavým pozorováním a zvažováním faktů jazykových. » [traduit en français par K.D.]

${ }^{62}$ Vítězslav Nezval, Průvodce mladých básníků, in J. Levý, České theorie překladu, SNKLHU, 1957, p. 639. « čte [se] jako původní báseň ». [traduit en français par K.D.]

${ }^{63}$ Ibidem, p. 638.
} 
ČAPEK Karel (1914), Guillaume Apollinaire, Přehled, le 20 janvier 1914, nº 15, p. 271-272.

ČAPEK Karel (1964), Francouzská poezie nové doby, Praha, Československý spisovatel.

ČAPEK Karel (1993), Spisy: Korespondence I, II, Praha, Československý spisovatel.

ČERNÝ Václav (1928-29), Guillaume Apollinaire, Výbor z básní, Host, 8, no 4 , p. 188.

DRSKOVÁ Kateřina (2011), À propos des traductions tchèques du Bateau ivre de Jean-Arthur Rimbaud, Écho des études romanes, VII, $\mathrm{n}^{\circ}$ 2, p. 31-44.

HLÁvKA Miloš (1928-29), Kritika tvůrčí a vědecká, Rozpravy Aventina, 4, č. 3940, p. 395.

JEDLIČKA Alois, Jazykové a jazykovědné zájmy Karla Čapka, Naše řeč, 74, 1991, p. 6-15.

JEŽEK Jiří, (1923-24), G. Apollinaire, Host, 3, nº 6-7, p. 137-142.

KROUPA Adolf (dirigé par, 1981), Apollinaire známý neznámý: výbor z básnického díla, Praha, Odeon.

LEHÁR Jan ; STICH Alexandr ; JANÁČKOVÁ Jaroslava ; HoLÝ Jiří (2008), Česká literatura od počátků $k$ dnešku, Praha, NLN.

LEVÝ Jiří (1971), Čapkovy překlady ve vývoji českého překladatelství a českého verše, in Bude literární věda exaktní vědou? Výbor studií, Praha, Československý spisovatel, p. 227-258.

MAŠEK Jiří (1929), G. Apollinaire: Básně, Literární noviny, 3, č. 11, 30.5.1929, p. 3.

MAŠEK Jiří (1929), Chyba lávky - Chyba Hlávky!, Literární noviny, 3, č. 18, 17.10.1929, p. 3.

MUKAR̆OvSKÝ Jan (1936), K novému vydání Francouzské poesie K. Čapka, Slovo a slovesnost, $2, \mathrm{n}^{\circ} 4$, p. 253-255.

MuKAR̆OvsKÝ Jan (dir., 1995), Dějiny české literatury IV, Praha, Victoria Publishing.

Nezval Vítězslav (1957), Průvodce mladých básníků, in J. Levý, České theorie překladu, SNKLHU.

Nezval Vítězslav (1964), Moderní básnické směry Praha, Československý spisovatel.

PEŠAT Zdeněk (1966), Apollinairovo Pásmo a dvě fáze české polytematické poezie, in Struktura a smysl literárního díla, Praha, Československý spisovatel, p. 109-125.

POHORSKÝ Aleš (1987), Pásmo, in Poetika české meziválečné literatury, Praha, Československý spisovatel, p. 56-79.

SKC - Souborný katalog České republiky [en ligne], Národní knihovna České republiky, <http://www.caslin.cz/uvod/view?set_language=cs >

STUPKA Vladimír (1960), Autour des traductions tchèques d'Apollinaire, Philologica pragensia, 2, $\mathrm{n}^{\mathrm{o}}$ 3, Praha, Nakladatelství ČSAV, p. 71-85.

STUPKA Vladimír (1960), Tableau des traductions tchèques d'Apollinaire, Sborník prací brněnské univerzity, 9, D7, p. 209-219. 
TeIGE Karel (1928-29), Guillaume Apollinaire (k desátému výročí jeho smrti), Rozpravy Aventina, 4, $\mathrm{n}^{\circ} 11$, p. 105-108.

TeIGE Karel (1966), Guillaume Apollinaire a jeho doba, in Karel Teige, Výbor $z$ díla I : Světa stavby a básně : Studie z dvacátých let, Praha, Československý spisovatel.

Cétoine dorée, in Wikipédia, l'Encyclopédie libre [en ligne], cité le 4 août 2015. <https://fr.wikipedia.org/wiki/C\%C3\%A9toine_dor\%C3\%A9e>

[TEIGE Karel] (1928-29), Guillaume Apollinaire : Básně, ReD, 2, nº 8, p.267.

TOURET Michèle et al. (2000), Histoire de la littérature fr. du XX ${ }^{e}$ s., tome I, Presses universitaires de Rennes. 